\title{
Salmonella enterica serovar Stanley intrauterine infection in a stillborn calf - case report
}

\author{
Paulina Jawor ${ }^{1}$, Tadeusz Stefaniak ${ }^{1}$, Zenon Sołtysiak ${ }^{2}$, Stanisław Dzimira ${ }^{3}$, \\ Michał Bednarski ${ }^{4}$

\begin{abstract}
${ }^{1}$ Wroclaw University of Environmental and Life Sciences, Faculty of Veterinary Medicine, Department of Immunology, Pathophysiology and Veterinary Prevention,

${ }^{2}$ Department of Internal Medicine and Clinic of Diseases of Horses, Dogs and Cats, ${ }^{3}$ Department of Pathology, ${ }^{4}$ Department of Epizootiology and Clinic of Birds and Exotic Animals, Wroclaw, Poland
\end{abstract}

Received April 8, 2013

Accepted August 28, 2013

\begin{abstract}
The aim of this study was to report the response to a bacterial intrauterine infection in a calf. A stillborn calf, dam's blood and amniotic fluid were submitted for examination. Necropsy of the calf was performed and $\mathrm{IgG}_{1}, \mathrm{IgG}_{2}$, IgM, IL-6 in the calf's serum, Il-6 in the dam's serum, and amniotic fluid were estimated. During necropsy, fluid in pleural and peritoneal cavities stained with haemoglobin and diagonal fissures in the aortic arch endothelium were found. Salmonella enterica serovar Stanley was isolated from the spleen, lungs and abomasal fluid. Histopathological examination revealed: inflammatory infiltration and haemorrhages in lungs and small perivascular haemorrhages in the frontal cortex and near the lateral ventricles of the white matter, focal gliosis in the frontal cortex, and neuronal atrophy of the dentate gyrus with diffuse glial cells proliferation in the brain. The concentration of $\operatorname{IgG}_{1}$ in the calf's serum was increased and IL-6 was detected in both the dam's blood and amniotic fluid. Necropsy, bacterial culture and immunological findings in the stillborn calf confirmed the intrauterine infection with Salmonella Stanley as the cause of death. Meanwhile, neonatal diarrhoea (incidence $46 \%$ ) with high mortality (54\%) occurred on the same farm. From diarrhoeic calves, Salmonella Typhimurium and $S$. Enteritidis were isolated. Based on available literature this is the first evidence of Salmonella enterica serovar Stanley isolation from a stillborn calf.
\end{abstract}

Brain injury, Salmonella sp., diarrhoea, immunoglobulin, cattle

In many countries, the rate of stillborn calves has increased in the last decades. The rate of stillborn calves on Polish dairy farms is estimated between 7.4 and 7.8\% (Stefaniak et al. 2011). Stillbirth is commonly defined as the death of a calf at birth or within $24 \mathrm{~h}$ after birth, after at least 260 days of gestation (Berglund et al. 2003). The most common causes of stillbirths are perinatal hypoxia and injury, immaturity, intrauterine infection, metabolic disturbances and congenital malformations. Causative diagnosis is difficult and the causes remain unknown in more than $30 \%$ of cases (Berglund et al. 2003). The role of intrauterine bacterial infection as a cause of stillbirth in calves is probably underestimated. Intrauterine infection in human foetuses causes brain injury associated with foetal inflammatory response syndrome (FIRS), an inflammatory response that can progress toward multiple organ dysfunction, septic shock and death. Intrauterine infection may lead to the stimulation of cytokine network, which in turn can cause white matter brain damage (Bashiri et al. 2006). White matter damage (WMD) in infants is strongly associated with an adverse outcome. There are two potential, but not mutually exclusive aetiologies of WMD. Firstly, infection/inflammation as part of FIRS (pronounced infiltration of inflammatory cells into the brain and focal microglia/macrophages in response to lipopolysaccharide); secondly, ischaemia-reperfusion (usually no cellular infiltrates are seen and the microglia response is more diffuse).

Address for correspondence:

Dr. Paulina Jawor

Wroclaw University of Environmental and Life Sciences

Faculty of Veterinary Medicine

Phone: +48 713205240

Fax: +48 713205246

C.K. Norwida 31 Str., 50-375 Wroclaw, Poland

-mail: paulina.jawor@up.wroc.p

http://actavet.vfu.cz/ 
In the brains of stillborn calves, subdural as well as periventricular haemorrhages have been considered to be the consequence of foetus ischaemia during delivery (Langanke et al. 1992), but microhaemorrhages may also be present in aborted foetuses in cases of e.g. bovine herpesvirus 1 infection (Brower et al. 2008). The salmonellas are also a wellrecognized cause of abortion in cattle, with Salmonella Dublin being the most commonly isolated. Nevertheless, other serotypes may be associated with abortion (Hinton 1977; Carpenter et al. 2006). The foetal calf is able to recognize antigens and produce IgM antibody from at least the $90^{\text {th }}$ day of gestation and $\operatorname{IgG}$ and $\operatorname{IgA}$ antibodies from the $111^{\text {th }}$ day (Ellis et al. 1978). Sawyer et al. (1973) carried out a quantitative study of IgM and IgG values in the sera of precolostral calves and experimentally and naturally infected foetuses. Immunoglobulins produced by an in utero infected bovine foetus significantly exceed the normal level $(<0.3 \mathrm{~g} \mathrm{Ig} / \mathrm{l})$ determined in healthy, precolostral calves.

The aim of this study was to report the inflammatory response to Salmonella Stanley intrauterine infection and brain injury in a stillborn calf.

\section{Case report}

The study was carried out on a stillborn Polish Holstein-Friesian heifer-calf from a twin pregnancy. The percentage of stillborn calves was $7.5 \%$ on the 460 head farm not vaccinated against Salmonella sp. The cow calved 10 days before the expected term in December 2010 and both calves were dead at delivery. One stillborn calf, dam serum and the amniotic fluid were submitted to the Department of Pathology of Wroclaw University of Environmental and Life Sciences. The amniotic fluid was aspirated from foetal membranes hanging down from the dam's vulva.

During the necropsy of the stillborn calf, transudate fluid stained with haemoglobin was found in the pleural $(50-100 \mathrm{ml})$ and peritoneal $(200-250 \mathrm{ml})$ cavities. The lungs were congenitally collapsed. Diagonal fissures in the aortic arch endothelium were seen with ruptures grossly visible and length from $3 \mathrm{~mm}$ to $10 \mathrm{~mm}$. Moreover, haemorrhages had occurred in the adventitia of umbilical blood vessels. The spleen was moderately oedematous. The mucous membrane of the abomasum, the small intestine, both kidneys and suprarenal glands were congested.

During necropsy, samples of lungs and the whole brain (between 6 and $8 \mathrm{~h}$ after the calf was born) were taken. Tissue samples were placed in $10 \%$ neutral buffered formalin solution and later paraffin embedded, and the sections were stained with haematoxylineosin. The brain was sliced in five places according to neuropathological examination schedule. Brain histopathological examination showed that the leptomeningeal blood vessels were hyperaemic and inflammatory cells' infiltration in the adventitia layer was observed. Parietal thrombi were also present in a few leptomenigeal vessels (Plate II, Fig. 1a). Small perivascular haemorrhages were found in the frontal cortex and near the lateral ventricles of the white matter (Plate II, Fig. 1b), as well as focal gliosis in the frontal cortex (Plate II, Fig. 1c) and neuronal atrophy of the dentate gyrus (Plate II, Fig. 1d) with diffuse glial cells proliferation (Plate II, Fig. 1e). Histopathological examination of lungs showed airless pulmonary tissue, inflammatory infiltration and haemorrhages. Both focal and diffuse inflammatory infiltrations were observed (Plate III, Fig. 2).

Sections of inner organs (spleen, lung, liver, kidney) and abomasal fluid were cultured bacteriologically on blood, chocolate, and MacConkey agar plates and brain heart infusion. The culture yielded non-lactose fermenting colonies that were confirmed as Salmonella Stanley by biochemical methods and serological typing (PN-EN ISO 6579:2003). A few colonies of Salmonella Stanley were detected in the spleen and numerous colonies in the lungs and abomasal fluid; cultures of liver and kidney were negative.

$\mathrm{IgG}_{1}, \mathrm{IgG}_{2}$ and IgM immunoglobulins were estimated in the calf's serum by radial 
immunodiffusion (Mancini et al. 1965). The concentration of IL-6 in the calf's and the dam's serum and in the amniotic fluid were estimated using ELISA (Thermo Scientific, USA; ELISA was validated to bovine interleukin 6 by the producer). The concentration of $\operatorname{IgG}_{1}$ in the calf's serum was $0.62 \mathrm{~g} / \mathrm{l}$; only a trace of $\mathrm{IgM}$ was found, and $\mathrm{IgG}_{2}$ was not detected. The concentration of IL-6 was $0.215 \mathrm{ng} / \mathrm{ml}$ in the calf's serum, $1.62 \mathrm{ng} / \mathrm{ml}$ in the dam's serum, and $1.84 \mathrm{ng} / \mathrm{ml}$ in the amniotic fluid.

A few days after necropsy we visited this farm due to an outbreak of severe neonatal diarrhoea (incidence 46\%) among the calves, with high mortality (54\%) despite treatment. During the inspection, presence of large number of birds (mostly pigeons) and traces of rodent faeces were observed. Following samples were taken for bacteriological culture: rectal swabs from four diarrhoeic calves and dam of stillborn calves, from the cloaca of two pigeons, swabs from the feed bunk in lactating and calving cows' pens, swabs from the floor in the calf barn and calving pen, samples of milk replacer and a swab from the mixer wagon. Results from bacteriological examination of samples taken at the farm are shown in Table 1.

Table 1. Results of bacterial culture from samples taken at the dairy farm.

\begin{tabular}{|c|c|}
\hline Sample & Isolated bacteria \\
\hline $\begin{array}{l}\text { Rectal swabs from diarrhoeic } \\
\text { calves }(\mathrm{n}=4)\end{array}$ & $\begin{array}{l}\text { E. coli (4 cases), Enterococcus spp. (4 cases), Salmonella } \\
\text { Typhimurium ( } 2 \text { cases), Salmonella Enteritidis ( } 1 \text { case) }\end{array}$ \\
\hline $\begin{array}{l}\text { Rectal swab from dam of } \\
\text { stillborn calf }(n=1)\end{array}$ & $\begin{array}{l}\text { E.coli EPEC serotype O111, Staphylococcus aureus and B-haemolytic } \\
\text { Streptococcus }\end{array}$ \\
\hline $\begin{array}{l}\text { Cloacal swab from two } \\
\text { pigeons }(\mathrm{n}=2)\end{array}$ & E. coli, Enterococcus spp., Proteus mirabilis \\
\hline Feed bunk swab $(\mathrm{n}=1)$ & individual colonies of E. coli and Enterococcus spp. \\
\hline $\begin{array}{l}\text { Swab from floor in calving } \\
\text { pen }(\mathrm{n}=1)\end{array}$ & E. coli, Enterococcus spp., Proteus mirabilis \\
\hline $\begin{array}{l}\text { Swab from floor in calf } \\
\text { barn }(n=1)\end{array}$ & E. coli, Enterococcus spp., Proteus mirabilis \\
\hline Milk replacer (30 g powder) & no growth \\
\hline $\begin{array}{l}\text { Swab from mixer wagon } \\
(\mathrm{n}=1)\end{array}$ & $\begin{array}{l}\text { Enterococcus spp., Bacillus spp. (individual colonies), Staphylococcus } \\
\text { coagulase neg. (individual colonies), E. coli (individual colonies), } \\
\text { Proteus mirabilis }\end{array}$ \\
\hline
\end{tabular}

\section{Discussion}

The presence of large volumes of transsudate in the pleural and peritoneal cavities might be associated with dystocia. Since the lungs were congenitally collapsed, the calf died before calving. There was no sign of decomposition in the inner organs. An interesting finding was the diagonal fissures in the endothelium of the aortic arch, which are frequently found in calves that died due to Gram-negative infections (Balbierz et al. 1990). Isolation of $S$. Stanley in bacterial cultures confirmed intrauterine infection in this case. Isolation of the bacteria from stillborn calves has not been reported, yet. A case of Salmonella enterica serovar Stanley skin infection has been described in a veterinary surgeon who assisted at a difficult delivery (Lazarus et al. 2007). Visser (1991) described two cases of skin infections in veterinarians following delivery of emphysematous dead calves. In the first case, $S$. enterica serovar Virchow was isolated from the human (skin pustules) and from the cow's milk. In the second case, S. enterica serovar Dublin was isolated in pure culture from the pustules on the veterinarian's skin and from the cow's vagina and rectum. In both studies described above, bacteriological culture of samples obtained from the calves was not 
performed. The presence of FIRS in the calf was indicated by the results of histopathological examination of the brain: inflammatory cells infiltration of leptomenigeal vessels, focal gliosis, and colliquative necrotic foci with microglia cells. However, a large volume of transudate in the pleural and peritoneal cavities, and brain foci of colliquative necrosis may also be associated with hypoxia and brain ischaemia followed by regenerative processes. Lung histopathological findings indicated the presence of severe pneumonia, confirming the presence of intrauterine infection. Therefore, we cannot exclude that hypoxia and brain ischaemia occurred at the same time as intrauterine infection.

The elevated concentration of immunoglobulins in the serum indicated a humoral immune response to antigenic stimulation in utero. The IgG exceeded twice the upper level of immunoglobulins in healthy precolostral calves (Sawyer et al. 1973). It is difficult to interpret the IL-6 concentrations in the calf's serum and amniotic fluid, due to the lack of references in cattle, but the concentration in the dam's serum seems normal for this period (Ishikawa et al. 2004).

Among bacteria isolated from samples taken on the farm, Salmonella enterica subsp. enterica serovar Typhimurium and $S$. enterica subsp. enterica serovar Enteritidis belonged to undesirable pathological flora. Cattle are considered to be a reservoir of $E$. coli serotype O111 and a source of infection to humans, but the isolated strain was not characterized for the presence of virulence factors; therefore, it is difficult to determine its importance as a threat. Staphylococcus aureus may be isolated from rectal swabs from clinically healthy cattle (Dimitracopoulos et al. 1977). Both mentioned microorganisms were isolated from the dam of the stillborn calf. Normal bacterial microflora was isolated from pigeons, feed bunk, the floor in the calving cows' pen, the floor in the calf barn and a the mixer wagon. Isolation of two (or more) different serovars of Salmonella on the same farm was described before. In a study by Kirchner et al. (2012) on a dairy farm with Salmonella Dublin infection, not only $S$. Thyphimurium but other serovars, e.g. Enteritidis, Agama, Newport and Saintpaul were detected. Even though there was no isolation of Salmonella from pigeons and Salmonella was not detected on the farm before, we cannot exclude the wild birds as a potential source of infection. Other than bird droppings, sources of infection like manure stores or other sick animals could be possible as well (Fossler et al. 2005).

In conclusion, the probable cause of the calf's death was intrauterine infection followed by FIRS and development of brain and meningeal injury. Despite greater perinatal mortality and more common dystocia in twin calves (Sawa et al. 2012), veterinarians should always be aware of the possibility of intrauterine infection. Frequently occurring difficulties in the identification of a causative agent suggest that indirect evidence (presence of FIRS) may be an interesting method of confirming/excluding intrauterine infection as the cause of stillborn or weak calf syndrome. This should increase the detection rate of intrauterine infection cases where the infectious agent was not diagnosed.

\section{References}

Balbierz H, Nikołajczuk M, Michalska Z, Nowacki W 1990: The aortic arch alterations in course of bacterial infections in calves (in Polish, English abstract). Arch Vet Pol 30: 155-161

Bashiri A, Burstein E, Mazor M 2006: Cerebral palsy and fetal inflammatory response syndrome: a review. J Perinat Med 34: 5-12

Berglund B, Steinbock L, Elvander M 2003: Causes of stillbirth and time of death in Swedish Holstein calves examined post mortem. Acta Vet Scand 44: 111-120

Brower A, Homb KM, Bochsler P, Porter R, Woods K, Ubl S, Krueger D, Cigel F, Toohey-Kurth K 2008: Encephalitis in aborted bovine fetuses associated with Bovine herpesvirus 1 infection. J Vet Diagn Invest 20: 297-303

Carpenter TE, Chriel M., Andersen MM, Wulfson L, Jensen AM, Houe H, Greiner M 2006: An epidemiologic study of late-term abortions in dairy cattle in Denmark, July 2000-August 2003. Prev Vet Med 77: 215-229

Dimitracopoulos G, Kalkani-Boussiakou H, Papavassiliou J 1977: Animal fecal carriership and biotypes of Staphylococcus aureus. Appl Environ Microbiol 34: 461-464 
Ellis WA, Logan EF, O’Brien JJ 1978: Serum immunoglobulins in aborted and non-aborted bovine foetuses. Clin Exp Immunol 33: 136-141

Fossler CP, Wells SJ, Kaneene JB, Ruegg PL, Warnick LD, Eberly LE, Godden SM, Halbert LW, Campbell AM, Bolin CA, Zwald AM, 2005: Cattle and environmental sample-level factors associated with the presence of Salmonella in a multi-state study of conventional and organic dairy farms. Prev Vet Med 67: 39-53

Hinton M 1977: The diagnosis of Salmonella abortion in cattle with particular reference to Salmonella dublin. A review. J Hyg (Lond) 79: 25-38

Ishikawa Y, Nakada K, Hagiwara K, Kirisawa R, Iwai H, Moriyoshi M, Sawamukai Y 2004: Changes in interleukin-6 concentration in peripheral blood of pre- and post-partum dairy cattle and its relationship to postpartum reproductive diseases. J Vet Med Sci 66: 1403-1408

Kirchner M, McLaren I, Clifton-Hadley FA, Liebana E, Wales AD, Davies RH 2012: A comparison between longitudinal shedding patterns of Salmonella Typhimurium and Salmonella Dublin on dairy farms. Vet Rec 171: 194. doi: 10.1136/vr.100865. Epub 2012 Aug 2

Langanke M, Steinhardt M, Bünger U, Fiebig U, Kutschke J, Gollnast I 1992: Birth injuries in calves and perinatal calf losses in a large dairy herd (in German, English abstract). Tierärztl Prax 20: 462-468

Lazarus R, Waghorn D, Nash C 2007: Cutaneous Salmonella infection. Scand J Infect Dis 39: 257-258

Mancini G, Carbonara AO, Heremans JF 1965: Immunochemical quantitation of antigens by single radial immunodiffusion. Immunochemistry 3: 235-254

PN EN ISO 6579:2003 Microbiology of food and animal feeding stuffs - horizontal method for the detection of Salmonella spp. (in Polish)

Stefaniak T, Jawor P, Sołtysiak Z, Bednarski M 2011: Weak calf syndrome (in Polish, English abstract). Magazyn Wet Choroby Bydła-Monografia: 1062-1065

Sawa A, Bogucki M, Krężel-Czopek S 2012: Reproduction performance of cows with single, twin and triplet calves. Acta Vet Brno 81: 347-352

Sawyer M, Osburn BI, Knight HD, Kendrick JW 1973: A quantitative serologic assay for diagnosing congenital infections of cattle. AJVR 34: 1281-1284

Visser IJR 1991: Cutaneous salmonellosis in veterinarians. Vet Rec 129: 364 
Plate II

Jawor P. et al.: Salmonella enterica ... pp. 363-367
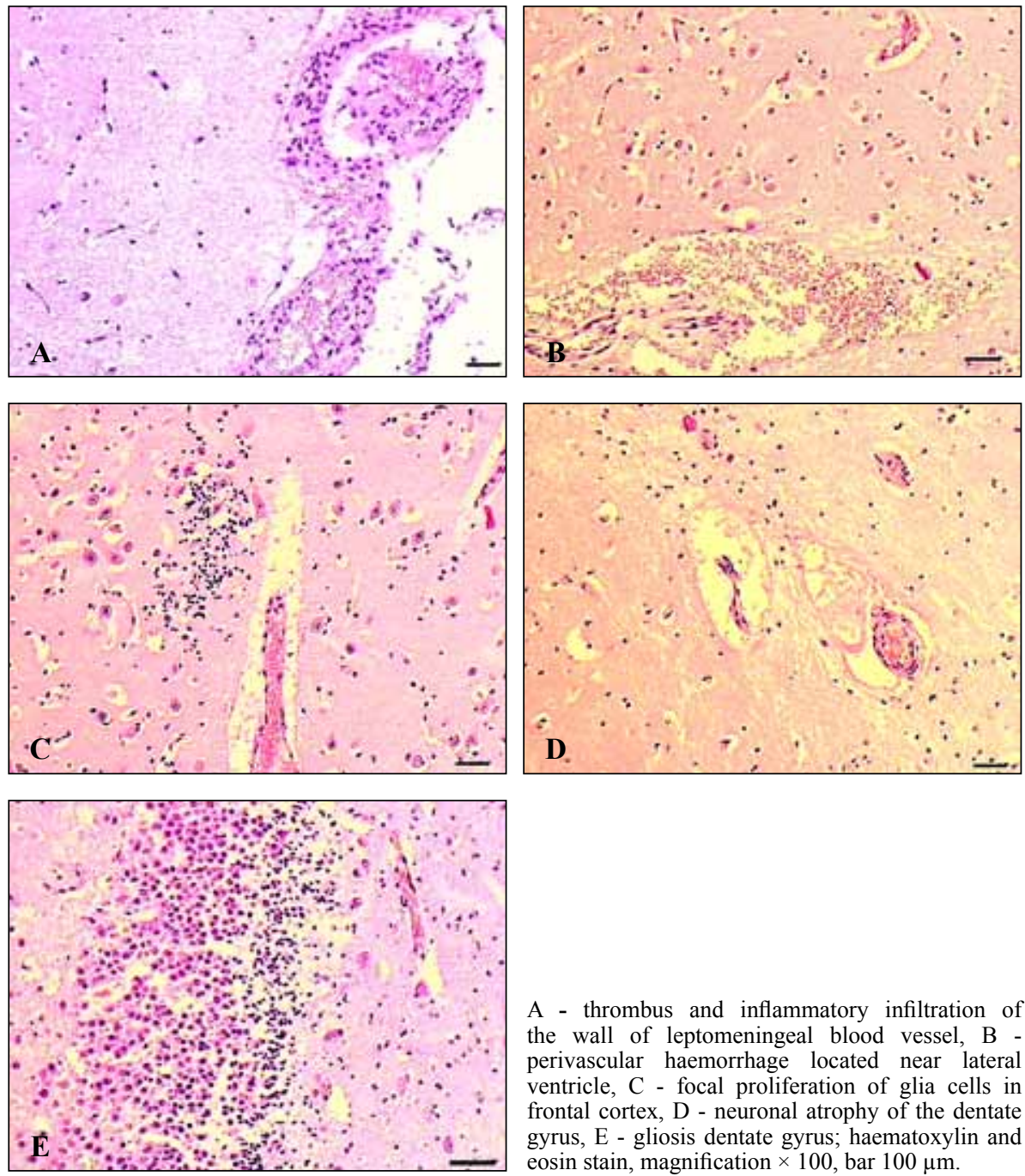

A - thrombus and inflammatory infiltration of the wall of leptomeningeal blood vessel, B perivascular haemorrhage located near lateral ventricle, $\mathrm{C}$ - focal proliferation of glia cells in frontal cortex, D - neuronal atrophy of the dentate gyrus, E - gliosis dentate gyrus; haematoxylin and eosin stain, magnification $\times 100$, bar $100 \mu \mathrm{m}$.

Fig. 1. Histopathological findings in the brain of a stillborn calf. 
Plate III

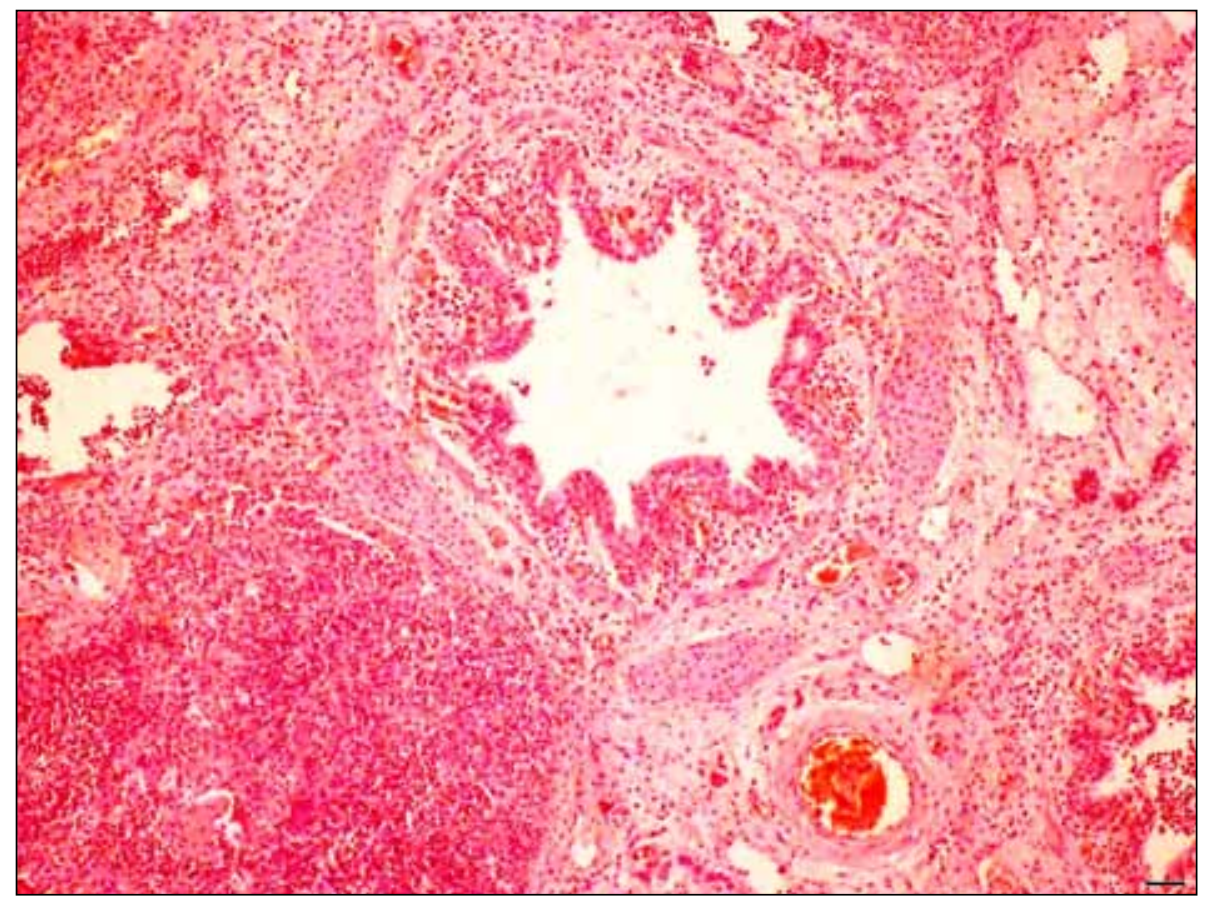

Fig 2. Focal (bottom left corner) and diffuse inflammatory infiltration of airless pulmonary tissue, oedema of the bronchial mucosa of a stillborn calf (haematoxylin and eosin stain, bar $200 \mu \mathrm{m}$ ). 